\title{
Análise do modelo de apresentação de dados financeiros a investidores por empresas de capital aberto
}

Análisis de la presentación de la información financiera a los inversores por las empresas que cotizan en bolsa

Analysis of the presentation of financial information to investors by publicly traded companies

\author{
José Eduardo SANTAREm Segundo, Gabriela Alves MANZONI
}

Universidade de São Paulo - USP

santarem@usp.br, gabi.manzoni@hotmail.com

\section{Resumen}

Uno de los elementos esenciales de la política de transparencia y buen gobierno de las empresas que operan en los mercados de valores de todo el mundo es la presentación de la información a sus inversores. Para ello, algunos países han adoptado el estándar Extensible Business Reporting Language (XBRL), un modelo de datos para estandarizar y proporcionar datos financieros en internet. En este trabajo se ha analizado el procedimiento utilizado por las veinte principales empresas brasileñas que se negocian en la Bolsa de Valores de Sao Paulo (BM\&F Bovespa). Se utilizó una metodología exploratoria, que incluyó el envío de encuestas a dichas empresas. Como resultado, se constata que las empresas brasileñas, a pesar de conocer su existencia, aún no lo utilizan para la divulgación de su información financiera.
\end{abstract}

Palabras clave: Información financiera. XBRL. Relaciones con los inversores. Empresas cotizadas. Internet.

\section{Introdução}

A estabilização da economia brasileira ocorrida a partir dos anos 90 trouxe grandes benefícios ao mercado de capitais. Pessoas com forte potencial de investimento, que não se arriscavam em bolsa de valores, passaram a flertar com essa modalidade de negócio, iniciando assim, um movimento de grande expansão no número de investidores. Porém, para que a confiança desses novos investidores fosse maximizada, foram demandadas algumas mudanças em prol da transparência, o que se convencionou chamar de Governança Corporativa, que caracteriza-se como o conceito de transparência na prestação de informações, ou seja, a divulgação clara, consistente e confiável de atos e fatos relevantes relacionados à empresa. Entende-se como sendo atos ou fatos relevantes (Abrasca, 2007):

\begin{abstract}
One of essential items in the policy of transparency and governance for companies that operate on the worldwide stock exchanges is the presentation of information to their investors. Some countries have already adopted the standard Extensible Business Reporting Language (XBRL), a data model to standardize and provide financial data on the Internet. The main objective of this work was to analyze how the 20 largest Brazilian companies in the São Paulo Stock Exhange (BM\&F Bovespa) disclose their financial information in the internet, using an exploratory methodology that included a survey among these companies. As a result, it was found that the Brazilian companies, despite knowing XBRL, do not use it for publishing their financial information on the Internet.
\end{abstract}

Keywords: Financial information. XBRL. Investor relations. Publicly traded companies. Internet.

[...] todos os atos e fatos ocorridos nos negócios da companhia ou de suas controladas, inclusive decisões do acionista controlador e deliberações da assembléia geral ou dos órgãos de administração da companhia.

A busca pela segurança nos dados financeiros induziu as principais companhias negociadas na bolsa a estabelecerem em seus sistemas, processos como a Governança Corporativa, pois ela funciona como sendo uma aplicação eficiente para se divulgar informações, passando a transmitir dados de extrema importância para acionistas.

Admite-se que ocorreu grande evolução na qualidade da disseminação de informações das companhias brasileiras, mas para atingirmos patamares de mercados desenvolvidos, que apresentam alto grau de transparência como o norte-americano ou o alemão é necessário que a relação com os investidores $(\mathrm{RI})$ seja realizada de forma mais clara e sistemática. 
As empresas e suas equipes de relação com investidores podem fazer uma importante diferença ao fornecer informações valiosas através do mercado. Claramente, o objetivo de toda empresa aberta deve ser fornecer informações do maior valor tanto nos seus registros obrigatórios de disclosure como nos seus esforços de comunicação voluntária, buscando atingir eficazmente a mais ampla audiência de investimento (Mahoney, 2009).

Essa confiabilidade que a equipe de RI busca passar aos seus investidores, contribui com forte expectativa aos meios ambiciosos do mercado que vem surgindo, contribuindo portanto, a um olhar mais minucioso as tecnologias impostas para a sociedade, em que algumas empresas tomaram iniciativas que melhoraram a comunicação com seu acionista através da facilitação do acesso aos seus dados, aumentando assim o grau de governança corporativa além da praxe.

Existe uma tendência de melhora da qualidade das informações apresentadas, amparada pelas tecnologias de informação e de comunicação entre empresas e investidores, porém houve um simultâneo retrocesso, uma vez que foram observadas falhas nos dados disponíveis à sociedade, por isso a solução muitas vezes seria usufruir de uma nova alternativa, como a linguagem XBRL. A linguagem XBRL é uma das variantes da linguagem XML com o propósito de se tornar a linguagem padrão para divulgação de resultados financeiros. A linguagem é desenvolvida pelo consórcio XBRL internacional (Riccio et al., 2006).

A linguagem XBRL apresenta-se como uma estrutura de metadados, e é um caminho para facilitar um modelo padronizado de disponibilização da informação, de forma que os investidores possam ter o processo de recuperação da informação facilitado, incluindo a utilização de dispositivos tecnológicos para receber e tratar o conjunto de informações financeiras.

Atualmente o processo de recolher informações disponibilizadas pelas empresas de capital aberto é normalmente executado por empresas de consultoria especializadas. Utilizam um grande conjunto de pessoas e técnicas para captar os dados e constituir uma base operacional de cruzamento de valores, tendo como produto informações estratégicas para alimentar empresas e pessoas que pretendem investir em ações. Esse processo em grande parte das vezes é custoso e afasta o pequeno ou micro investidor que gostaria de ter acesso a esse tipo de informação para tomar suas decisões de investimento.
Portanto os dados disponibilizados pela área de RI das empresas, que deveriam ser uma informação de livre acesso, tornam-se produtos informacionais caros e elitizados, vendido por consultorias especializadas para investidores de maior potencial.

Esta pesquisa tem como objetivo principal identificar as vinte maiores empresas que negociam no mercado de ações na Bolsa de Valores de São Paulo (Bovespa), analisando como é feita disponibilização de informações financeiras a seus investidores através da internet. Objetiva ainda examinar quais as fontes e critérios usados para repassar todos os dados financeiros a seus investidores. Será ainda parte do objetivo desta pesquisa avaliar a linguagem XBRL e verificar a adesão ao uso da linguagem pelas empresas elencadas na pesquisa.

A metodologia desta proposta foi executada em três fases: a) constituição do corpus teóricometodológico da pesquisa; b) constituição do corpus empírico da pesquisa por meio do desenvolvimento de três estudos - identificação das 20 maiores empresas que negociam na BOVESPA, análise da forma como estas empresas divulgam seus dados financeiros na internet, e análise dos requisitos da linguagen XBRL e da evolução na disponibilização de informações financeiras pelo seu uso - ; e c) análise e interpretação dos resultados obtidos.

\section{XBRL: Extensible Business Reporting Language}

O conjunto e volume de informações financeiras produzidas pelas empresas atualmente, se analisadas, podem constituir uma percepção diferenciada sobre os rumos e possibilidades de futuro que a empresa terá.

Analisar todo esse conjunto de informações requer algum tipo de instrumento tecnológico que permita organizar e analisar os dados de forma mais eficiente. Os principais países do mundo têm se utilizado de um processo de organizar e constituir um padrão de formatação dos dados financeiros disponibilizados através do uso da linguagem XBRL.

XBRL, Extensible Business Reporting Language (Linguagem Extensiva de Publicação de Negócio) é uma linguagem para a comunicação eletrônica de dados financeiros e de negócios que está revolucionando a comunicação corporativa ao redor do mundo. Essa linguagem fornece benefícios importantes para a preparação, análise e comunicação de informações de negócios, além disso, oferece redução de custos, maior eficiência e maior precisão e confiabilidade para 
todos os envolvidos no fornecimento ou utilização de dados financeiros (XBRL International, 2010, tradução livre).

O início do desenvolvimento da XBRL data de abril de 1998, com Charles Hoffman, um CPA, Certified Public Accountant, da empresa Knight Vale and Gregory, em Tacoma, Washington, que passou a pesquisar o uso da linguagem XML para divulgar informações financeiras para divulgação eletrônica (Truman, 2004).

A linguagem XBRL foi desenvolvida com o propósito de agregar todos os formatos de relatórios financeiros e de negócios, com uma nomeação mais completa para fornecer ao usuário a capacidade de descarregar as informações de forma única favorecendo a geração de dados analíticos, reduzindo custos com a produção de demonstrativos financeiros, aumentando a capacidade de adequação às normas internacionais de contabilidade e, principalmente, conduzindo o usuário a um acesso mais facilitado e claro às informações apresentadas.

Essa disponibilização é estruturada através do uso da linguagem XML e segue regras de alta complexidade abordando uma ampla quantidade de informações.

É importante ressaltar que a funcionalidade de uma linguagem desta natureza em um país depende do desenvolvimento de uma taxonomia (estrutura informacional) adequada às necessidades da organização informacional financeira do país. As pesquisas no Brasil iniciaram-se com o TECSI-FEA-USP em 2011. Esse grupo de pesquisa também é responsável pelo desenvolvimento da primeira taxonomia brasileira.

A composição da linguagem XBRL, parte do princípio de entender como é o funcionamento dessa tecnologia dentro dos meios que ela será utilizada por um todo. Sua compreensão é baseada através de três conceitos essenciais, segundo (Hoffman 2010, p. 54):

- Especificações: São as normas em formato e sintaxe para definir regras de uso. O XBRL International criou um conjunto de especificações. O XBRL é entre outras coisas, um conjunto de especificações.

- Taxonomias: São classificações entre elementos, que permitem a um sistema organizar, extrair e analisar informações codificadas dentro de tal classificação.

- Instâncias: São os documentos XBRL que contém as informações financeiras publicadas. Como partes componentes têm: referências a taxonomias XBRL, contextos, unidades, fatos, comentários/notas explicativas.
No Brasil o Conselho Federal de Contabilidade (CFC), juntamente com o Comitê de Pronunciamentos Contábeis (CPC) tem organizado e liderado a implementação da linguagem no Brasil. Segundo o (CFC, 2012), O CFC, mediante Portaria $n^{\circ} 38 / 10$, instituiu a comissão com a finalidade de criar a jurisdição do XBRL no Brasil, credenciando o Conselho Federal de Contabilidade como entidade junto ao XBRL internacional.

A partir do momento em que a taxonomia brasileira for efetivada, dependerá ainda de uma política de uso para que as empresas passem efetivamente a usar de forma adequada a linguagem XBRL, disponibilizando seus dados financeiros neste formato.

\section{Disponibilização de dados financeiros}

A parte exploratória desta pesquisa iniciou-se com um acompanhamento do valor de mercado das empresas que operam na Bolsa de Valores de São Paulo (BOVESPA). Foi realizada uma média do valor de mercado durante o início do novembro de 2012. Este processo permitiu que fossem elencadas as 20 maiores empresa, em valor de mercado, que atuam na BOVESPA.

A partir desta análise foram identificadas e elencadas para esta pesquisa as seguintes empresas: Petróleo Brasileiro SA - PETROBRÁS, Companhia de Bebidas das Americas SA - Ambev, Companhia Vale do Rio Doce SA - VALE, Itaú Unibanco Holding - SA, Banco Bradesco SA, Obrascon Huarte Lain Brasil SA - OHL Brasil, Banco Santander (Brasil) SA, Banco Itau SA, Telefonica Brasil SA, Souza Cruz SA, Cielo SA, BRF - BRASIL FOODS SA, CCR SA, Gerdau Açominas SA, BM\&F Bovespa SA, Grupo Pão de Açúcar SA, Natura Cosméticos SA, Ultrapar Participações SA, Tractebel Energia SA e CPFL Energia SA.

Estas empresas atuam nos mais variados segmentos, apresentando ampla heterogeneidade de áreas de atuação, como por exemplo: petróleo, gás e energia; bebidas; mineração; banco; concessões publicas; gestão de participações societárias; telecomunicações; cigarros; serviços de pagamento; alimentos; rodovias e mobilidade urbana; metalurgia; bolsa de valores; comércio varejista; cosméticos; distribuição e armazenagem de químicos e líquidos; geração e comercio de energia elétrica.

Depois de identificadas as empresas a serem abordadas foi iniciado o processo averiguação de como as empresas disponibilizavam informações aos seus investidores. 
As empresas de capital aberto do mundo todo normalmente tem um site exclusivo ou então uma área dentro do site oficial da empresa que é direcionado aos investidores. $\mathrm{O}$ nome que se dá a este espaço é "Relação com Investidor", e nesta área são encontradas as principais informações financeiras da empresa.

Essa área é geralmente utilizada não apenas pelos sócios cotistas minoritários mas também pelos investidores que tem interesse em realizar novos investimentos na empresa. Nesse caso é perceptível que quanto mais claro e rico o conjunto de informações for, melhor será para a tomada de decisões a partir dos dados disponibilizados. Todas as 20 empresas listadas nesta pesquisa apresentam uma área de relação com investidor.

A seguir foi feita uma análise do formato de dados utilizado para disponibilização dos dados para os investidores. Das 20 empresas analisadas, 7 delas apresentam dados em dois formatos, sendo eles o XLS (Spreadsheet File Format) e o PDF (Portable Document Format), sendo que a grande maioria utiliza o formato PDF como único ou principal meio de divulgação das informações.

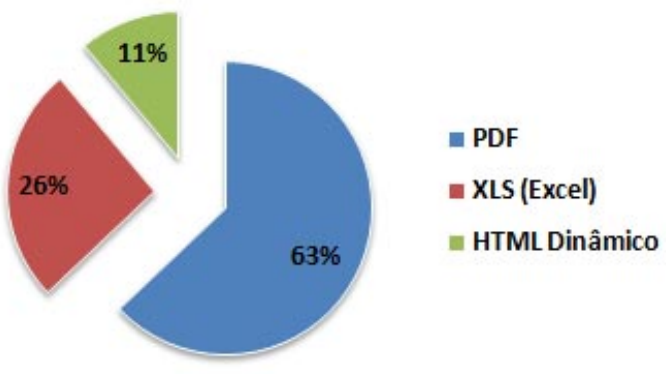

Figura 1. Formato de apresentação dos dados financeiros das empresas

Essa primeira análise nos leva a um conjunto de inconsistências:

- Nenhuma das empresas utiliza o formato XBRL.

- Nenhuma das empresas utiliza qualquer outro tipo de formado de dados padronizados em uma linguagem como a XML.

- Parte das empresas apresenta dados em formato HTML dinâmico que podem causar desconforto ao investidor, visto que a origem dos dados pode gerar listas diferentes a cada recuperação de dados.

- Apesar de ser um formato utilizado no mundo todo, o XLS baseado em Microsoft Excel é um formato de dados fechado e proprietá- rio. Apesar da possibilidade de abrir sem muitas perdas em outros aplicativos de planiIha eletrônica, para que seja utilizado de forma confiável exige a aquisição do Microsoft Office pelo Investidor.

- Os documentos em PDF apresentam características bem diferentes. Poucos estão no padrão internacional ISO 19005-1, PDF/A, que seria o mais adequado quando se pensa em utilizar o formato PDF. Alguns documentos em PDF ainda possuem restrições quanto a manipulação dos dados. Observa-se nesse caso que o uso do formato PDF é totalmente inadequado para que essa informação possa ser captada e utilizada em outro tipo de sistema de informação.

O modo e formato com que as empresas apresentam seus dados na área de RI gerou a necessidade de entender se estas empresas estão cientes de que o formato XBRL está em desenvolvimento e estudo para ser implementado como principal meio de divulgação de informações financeiras pelas empresas de capital aberto no Brasil.

Essa necessidade de identificação da situação do XBRL gerou a terceira parte desta pesquisa, que é baseado no contato com as empresas elencadas para verificação da situação atual de conhecimento e uso do padrão XBRL.

\section{Uso da linguagem XBRL}

Entender a situação de conhecimento e uso da linguagem XBRL pelas empresas inicia-se primeiramente por buscar entender qual é o setor responsável por esse tipo de inovação dentro do contexto de processos da empresa.

A princípio foi pensado que o início do processo deveria estar a cargo de uma equipe de Tecnologia da Informação (TI), posteriormente entendese que pudesse ser o setor de contabilidade da empresa o responsável por esse tipo de iniciativa. Como estamos tratando das 20 maiores empresas brasileiras que atuam na BOVESPA, entendemos que deveria haver uma equipe de Inovação, que talvez fosse a responsável pela proposição do uso da linguagem XBRL.

Portanto para que pudéssemos identificar o real uso e situação da linguagem XBRL nas empresas brasileiras constituímos um calendário e enviamos para as seguintes áreas das empresas: contabilidade, tecnologia da informação e inovação. Posteriormente também fizemos o contato para que o próprio e-mail ou formulário de "contato" na área de RI das empresas fossem notificados e entendessem a pesquisa que estava sendo realizada. 
Ao total foram formuladas 12 questões que tinham como principal objetivo identificar:

- Se a empresa sabe do que se trata a linguagem XBRL.

- Se a empresa sabe que a taxonomia XBRL brasileira está em fase final de implementação.

- Se a empresa, ou alguma área da empresa, está participando de alguma forma da discussão no Conselho Federal de Contabilidade sobre a taxonomia XBRL.

- Qual é a área da empresa responsável pela coordenação do projeto de implantação da linguagem XBRL.

- Se a empresa tem algum projeto de implementação da linguagem XBRL atualmente e se há previsão tempo para que os dados sejam disponibilizados neste formato.

- Se há algum tipo de discussão sobre o formato com a equipe de $\mathrm{TI}$ ou com a empresa responsável pelo sistema de gestão ERP para que o sistema receba adaptações para a emissão de dados financeiros neste formato.

Após o envio e contato com as empresas em três oportunidades diferentes tivemos com 0 prazo de praticamente 90 dias passado da primeira interação chegamos aos resultados.

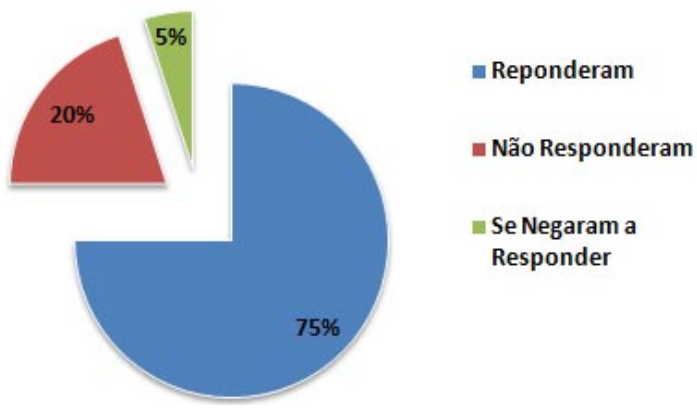

Figura 2. Respostas da empresas ao questionário

Como pode ser visto na Figura 2, das 20 empresas contatadas apenas 5 retornaram o contato positivamente, sendo que $20 \%$ delas manifestaram-se indicando que responderiam o formulário, $5 \%$ (1 empresa) se negou a responder o formulário e o restante simplesmente respondeu ao contato mas não respondeu o formulário, mesmo tendo ciência de que tratava-se de uma pesquisa acadêmica.

Após a baixa adesão a participação na pesquia, foi realizada a análise dos dados recebidos procurando identificar uma tendência situacional do uso da linguagem XBRL.
Das empresas que responderam ao questionário apenas uma delas indicou que a empresa conhece e pretende utilizar o formato XBRL nos próximos 3 anos.

Sobre o conhecimento sobre a elaboração da taxonomia brasileira para a linguagem XBRL, duas empresas se manifestaram indicando que sabem que está sendo desenvolvido, porém não tem qualquer participação ou contribuição no desenvolvimento.

Das empresas pesquisadas, apenas uma delas indicou que a área contábil é responsável pelo projeto de $\mathrm{XBRL}$, todas as outras como não conhecem a linguagem, também desconhecem quem poderia cuidar disso na empresa.

Não tivemos nenhuma resposta positiva a respeito do software que cuida da gestão da empresa estar preparado para emitir relatórios financeiros em formato XBRL.

\section{Considerações finais}

A situação de aparente crise financeira que envolve o mundo todo nos leva a refletir a respeito das mudanças que vem ocorrendo para melhorar a transparência e dirimir a fragilidade financeira das empresas de um modo geral.

O Brasil tem mudado sua posição no mundo como um país responsável financeiramente, isso possibilita as empresas de capital aberto a receber investimentos de capital estrangeiro e também de pequenos investidores

A bolsa de valores é um meio de permitir com que empresas recebam capital de terceiro com o intuito de evoluir e desenvolver-se ainda mais na sua área de atuação, criando novos rumos, aumentando sua capacidade de produção e principalmente gerando novos empregos e divisas para o país em que está inserida.

A área de Relação com Investidores nas empresas se coloca, portanto, como um recurso fundamental para que os novos investidores entendam o funcionamento e principalmente a saúde financeira da empresa. A área de Relação com Investidor deve ter um papel decisivo na qualidade e quantidade de informações que gera a respeito de todas as ações e processos em que a empresa está envolvida. A qualidade da informação apresentada pela área de RI das empresas pode impulsionar ou reduzir o fluxo de investimento realizado nas empresas.

Verifica-se que as informações produzidas pelas empresas na área de RI não segue um padrão de apresentação dos dados, o que inviabiliza o estudo comparativo entre dados dessas empresas através da recuperação automática de in- 
formações. Esses dados normalmente são manipulados por empresas de consultoria e afastam o pequeno investidor que não tem como comprar análises deste tipo. Padronizar o formato de disponibilização dos dados financeiros tende a melhorar o processo de recuperação da informação e principalmente facilitar a tomada de decisão dos novos investidores.

Entende-se que o uso da linguagem XBRL deverá ser o melhor caminho para que a área de $\mathrm{RI}$ forneça os resultados financeiros das empresas, visto que é um formato que permite interoperabilidade dos dados e leitura por qualquer tipo de equipamento, independente de sua arquitetura de hardware ou de software.

Identifica-se que o desenvolvimento da taxonomia brasileira para a linguagem XBRL deverá ser de fundamental importância para que as empresas passem a adotar prioritariamente o uso da linguagem XRBL como principal meio, não único, de divulgação de suas informações financeiras.

Sobre a pesquisa realizada com as principais e maiores empresas que atuam na Bolsa de Valores de São Paulo (BOVESPA), identificou-se uma falta de conhecimento sobre a linguagem XBRL. Todas as vinte empresas contatadas tiveram oportunidade de responder ao questionário, e algumas delas optaram por não responder. Isso representa um desconhecimento a respeito da linguagem XBRL e principalmente uma falta de ação dos setores que poderiam estar envolvidos com a proposição desta nova ferramenta.

Das empresas que responderam aos questionários, apenas uma delas sabe exatamente do que se trata a linguagem XBRL, porém não estão trabalhando na implementação da linguagem em sua área de RI. Esses dados nos mostram que as empresas brasileiras ainda estão longe de oferecer dados em formato XBRL para os investidores.

Verifica-se também que, apesar se ser de fundamental importância para as empresas a publicação das informações financeiras em formato $\mathrm{XBRL}$, nenhuma delas contribui ou participa do desenvolvimento da taxonomia. Isso implica que somente após a taxonomia se tornar oficial é que as empresas vão pensar em discutir a respeito do assunto e entender como deve funcionar a publicação de informações financeiras utilizando a linguagem XBRL. Essa falta de interesse ou de conhecimento sobre o desenvolvimento da linguagem e da taxonomia XBRL no Brasil indica fortemente que a área de RI das empresas, assim como a publicação de dados financeiros em formatos abertos e passíveis de recuperação por máquinas, não é uma prioridade das grandes empresas brasileiras que atuam na Bolsa de Valores.

Outra característica que nos leva a crer que há pouco interesse das empresas em realmente oferecer os dados em melhores condições é a identificação de que elas utilizam-se do formato PDF para apresentação dos dados. Grande parte delas não utiliza ISO 19005-1 PDF/A. Observa-se que a apresentação dos dados em formato PDF, independente da versão, contribui decisivamente para um processo dificultoso de recuperação de dados por máquinas.

Para finalizar, ressalta-se que grande parte das empresas publicam os dados em um formato fechado (XLS - Excel). Apesar do formato PDF ser um padrão aberto ISO 26300 , ele não é utilizado para publicação de dados em formato de planilha, sendo preterido por um formato proprietário.

A conclusão geral nos leva a dizer que apesar da necessidade das empresas em receber investimentos através da bolsa de valores, elas não olham para sua área de RI como um fator preponderante para que isso aconteça, indicando ainda que a informação financeira em formato aberto não se caracteriza como prioridade na busca por novos investidores.

Entende-se ainda que investir em um processo de melhoria na difusão de dados contábeis através do uso de uma estrutura informacional como a linguagem XBRL poderá contribuir decisivamente para o aumento da captação de recursos e movimentação das ações das empresas na bolsa de valores.

\section{Referencias}

ABRASCA - Associação Brasileira de Companhias Abertas (2007). Manual ABRASCA de controle e divulgação de informações relevantes. São Paulo: 2007.

Conselho Federal de Contabilidade. (2012). http://www.cfc. org.br/conteudo.aspx?codMenu=297. (2014-01-20)

Mahoney, W. F. (2009) O valor das relações com investidores. // Revista RI. Rio de Janeiro. 131 (abr. 2009) 2-16.

Riccio, E.; Sakata, M; Moreira, O. ;Quoniam, L. (2006). Introdução ao XBRL: nova linguagem para a divulgação de informações empresariais pela internet. // Ci. Inf. [online]. 35:3, 166-182. http://www.scielo.br/pdf/ci/v35n3/ v35n3a16.pdf (2014-03-10).

Truman State University (2011) Apresentation on XBRL. http://www2.truman.ed/ a1690/xbrl2.htm (2013-10-13).

XBRL International (2012). An Introduction to XBRL. www.xbrl.org. (2014-01-25).

Enviado: 2014-04-01. Segunda versión: 2014-07-10. Aceptado: 2014-07-10. 